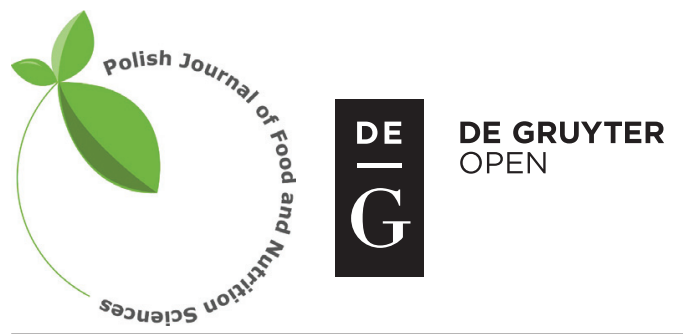

Pol. J. Food Nutr. Sci., 2018, Vol. 68, No. 2, pp. 171-177

DOI: $10.1515 /$ pjfns-2017-0021 http://journal.pan.olsztyn.pl

Original research article

Section: Nutritional Research

\title{
In Vitro Studies of Anti-Hemolytic and Cytotoxic Activity of Procyanidin-Rich Extract from the Leaves of Actinidia arguta
}

\author{
Sylwia Cyboran-Mikotajczyk ${ }^{1 *}$, Ákos Csonka², Joseph Molnar ${ }^{2}$, \\ Diana Szabó ${ }^{3}$, Jan Oszmiański ${ }^{4}$, Halina Kleszczyńska ${ }^{1}$ \\ ${ }^{1}$ Department of Physics and Biophysics, Wroclaw University of Environmental and Life Sciences, \\ Norwida 25,50-375 Wroctaw, Poland \\ ${ }^{2}$ Department of Medicinal Microbiology and Immunobiology, University of Szeged, Dóm tér 10, H-6720 Szeged, Hungary \\ ${ }^{3}$ Department of Otorhinolaryngology and Head-Neck Surgery, University of Szeged, \\ Tisza L. krt. 111, H-6725 Szeged, Hungary \\ ${ }^{4}$ Department of Fruit, Vegetable and Nutraceutical Technology, \\ Wroclaw University of Environmental and Life Sciences, Norwida 25, 50-375 Wroctaw, Poland
}

Key words: anti-hemolytic activity, cytotoxic activity, L5178Y cells, multidrug resistance, mini-kiwi (Actinidia arguta)

The leaves of mini kiwi (Actinidia arguta) are a rich source of phenolic compounds, in particular the B-type procyanidins that exhibit e.g. antioxidant, anticancer, antiviral, and anti-inflammatory activities. The aim of this study was to determine the biological activity of the extract from leaves of kiwi in relation to cells of erythrocytes and lymphoma. This activity was determined by studying kiwi leaves extract anti-hemolytic, cytotoxic and antiproliferative activity, and its ability to change the physical properties of the cell membrane and inhibit multidrug resistance of mouse lymphoma cells. It was shown that the extract ingredients bound to the cells, caused changes in erythrocyte shape and slightly affected the granularity and size of lymphoma cells. They effectively protected the red blood cells from oxidative damage, but were not toxic to lymphoma cells and did not affect their multidrug resistance. The extract of kiwi leaves is an effective antioxidant but it does not exhibit cytotoxic activity. Therefore, it can be used in the prevention of diseases, especially those related to oxidative stress.

\section{ABBREVIATIONS}

AAPH - 2,2'-azobis (2-amidinopropane) dihydrochloride; MDR - multidrug resistance;

MTT - 3-(4,5-dimethylthiazol-2-yl)-2,5-diphenyltetrazolium bromide;

RBCs - red blood cells

\section{INTRODUCTION}

Mini kiwi (Actinidia arguta, family Actinidiaceae, type: vine), commonly called the hardy kiwi, is a variety from northern China. Leaves of this plant are a rich source of phenolic substances, mainly composed of phenolic acids (neochlorogenic, chlorogenic and cryptochlorogenic acid), B-type procyanidin dimers, $(+)$ catechin and flavonols (quercetin glycosides, mostly triglycosides and kaempferol with 1, 2 or 3 sugar substituents) [Cyboran et al., 2014]. The presence of these substances ensures the biological activity, which includes antioxidant activity, hypoglycemic and antiproliferative action,

\footnotetext{
* Corresponding Author: Tel.: +48713205275; Fax: +48713205167;

E-mail: sylwia.cyboran@up.wroc.pl (S. Cyboran-Mikołajczyk, PhD)
}

and support of the digestive system [Montoya et al., 2014; Zuo et al., 2012].

One of the main causes of many pathological states and aging of the organism is believed to be disturbance of the oxidation-reduction balance that results in oxidative stress caused by a high concentration of free radicals [Kaur et al., 2014]. As a consequence, this leads to deterioration of basic life processes of cells, irreversible structural changes, mutations, and ultimately to cell death [Valko et al., 2007]. Therefore, currently, special attention is devoted to substances with high ability to reduce free radicals, mostly through looking for compounds of plant origin that do not show side effects on the organism.

Erythrocytes (RBC), due to their high content of unsaturated fatty acids and the ability of oxygen transfer [Chai et al., 2014], are constantly exposed to oxidative stress, which leads to changes in physical properties of the cell membrane responsible for integrity and mechanical properties of the cells, and consequently hinders their movement, in particular in the blood capillary veins. Oxidative damage occurs not only in membrane lipids but also in proteins, e.g. hemoglobin and spectrin, which in turn leads to irreversible structural changes and blood cell hemolysis [Becker et al., 1986; Buchwald et al., 2000]. The effect of oxidative stress on the physical properties and physi- 
ological functions of RBCs depends on the nature of the oxidative agent [Borst et al., 2000; Hale et al., 2011]. In our previous work we found that mini-kiwi leaves extract protects biological membranes from oxidation induced by different physicochemical factors, i.e. UVB and UVC radiation, and the AAPH compound [Cyboran et al., 2014]. This high antilipoperoxidant activity is mainly associated with the location of these compounds in the hydrophilic area of the membrane, where they form a protective barrier against diffusion of free radicals. Moreover, literature data indicate that some polyphenolic compounds can also effectively protect not only the lipids of biological membrane but also whole erythrocytes against oxidative damage [Fofie et al., 2014; Senguttuvan et al., 2014]. Polyphenols can also modify the shape of erythrocytes without showing cytotoxic effects [Bonarska-Kujawa et al., 2012; Suwalsky et al., 2006]. Our earlier research has shown the mini-kiwi leaves extract to be nontoxic in relation to erythrocytes and even to strengthen them in operating under the conditions of osmotic shock [Cyboran et al., 2014]. Therefore, the main aim of the present research was to determine whether polyphenolic compounds contained in the extract from the leaves of mini-kiwi have the ability to change erythrocyte shape and protect the cells from oxidative damage.

The second very important direction for research on substances of plant origin is their use in the prevention and treatment of cancer. Polyphenolic compounds, and in particular procyanidins, show the ability to inhibit the growth of various tumor cell lines, among others pancreatic, lung and colorectal cancer cells [Akhtar el al., 2009; Chung et al., 2012; Kaur et al., 2008; Zhao et al., 2013]. In addition, these compounds may also inhibit the multidrug resistance of tumor cells and increase efficacy of cytostatics [Zhao et al., 2013]. Multidrug resistance (MDR) of human tumors is one of the major reasons for the failure of chemotherapy in refractory cancer patients. The reversal of MDR in cancer cells can be improved by the application of chemotherapy in combination with resistance modifiers [Szabo \& Molnar, 1998; Szabo et al., 2000]. Great numbers of natural plant compounds, including procyanidins and kiwi fruit extract, have been shown to block the P-glycoprotein activity [He et al., 2009; Motohashi et al., 2002]. It was found that grape procyanidins reversed the MDR effect in blood-brain barrier by blocking the function of P-gp [He et al., 2009] and strongly inhibited P-gp expression by blocking MDR1 gene transcription. They also increased the intracellular accumulation of the P-gp substrate rhodamine-123 in A2780/T cells [Zhao et al., 2013]. In the literature there is a lack of studies on anticancer/cytotoxic and MDR-reversal activity of phenolics contained in the leaves of mini-kiwi. This prompted us to undertake a study on the influence of kiwi leaves extract (containing large amount of bioactive procyanidins) on the survival and multidrug resistance of lymphoma L5178 cells.

\section{MATERIALS AND METHODS}

\section{Plant material}

Mini-kiwi leaves (Actinidia arguta, family Actinidiaceae, type: vine) extract was obtained from the Department of Fruit, Vegetable and Plant Nutraceutical Technology, Wro- claw University of Environmental and Life Sciences, Poland. The Garden of Medicinal Plants herbarium of the Medical University in Wroclaw, Poland, was the provider of kiwi leaves used in the study. The research material was obtained from the stolon using a knife, and liquid nitrogen was used to freeze the leaves; and a dryer (Alpha 1-4 LSC, Christ, Germany) to freeze-dry them for $24 \mathrm{~h}$. The procedure for obtaining a polyphenolic extract from the leaves of mini kiwi and a detailed analysis of the composition of the extract were published earlier in the work by Cyboran et al. [2014].

\section{Cells and other compounds of interest}

The study was conducted on pig erythrocytes and L5178 mouse lymphoma $\mathrm{T}$ cells. The choice of pig erythrocytes was dictated by the fact that this cell's percentage share of lipids is closest to that of the human erythrocyte, and the blood was easily available. The choice of L5178 mouse lymphoma T cells was dictated by the fact that these cells are commonly used to study antitumor and MDR- reversal activity of chemicals.

The L5178 mouse lymphoma T cells (ECACC cat. no. 87111908; U.S. FDA, Silver spring, MD, USA) were treated as a model of cancer cells. The cells were cultured in McCoy's $5 \mathrm{~A}$ medium supplemented with L-glutamine and antibiotics (penicillin/streptomycin solution) at $37^{\circ} \mathrm{C}$ and in an atmosphere with $5 \% \mathrm{CO}_{2}$. The reagents for cell culture were purchased from Sigma Aldrich (Steinheim, Germany).

The oxidation inducer 2,2'-azobis(2-amidinopropane) dihydrochloride $(\mathrm{AAPH})$ and antioxidant standard $\mathrm{L}(+)$ ascorbic acid (AA) were purchased from Sigma-Aldrich, Inc., Steinheim, Germany. Verapamil and 3-(4,5-dimethylthiazol-2-yl)-2,5-diphenyltetrazolium bromide (MTT) were purchased from Sigma-Aldrich Quimica SA, Madrid, Spain. Procyanidin $\mathrm{B}_{3}$ was obtained from the Department of Fruit, Vegetable and Cereal Technology, Wroclaw University of Environmental and Life Sciences, Poland, and was extracted from pine. All other reagents were analytically pure.

\section{Spectrophotometric assay for anti-hemolytic activity}

To test the effect of extract on hemolysis induced by free radicals, RBCs were pre-incubated with varying concentrations of the extract $(1-8 \mu \mathrm{g} / \mathrm{mL})$ dissolved in ethanol at $37^{\circ} \mathrm{C}$ for $1 \mathrm{~h}$. In order to compare the anti-hemolytic activity of the extract with other substances the RBCs were also incubated, in the same conditions, with procyanidin $\mathrm{B}_{3}$ $(1-8 \mu \mathrm{g} / \mathrm{mL})$ and $\mathrm{L}(+)$ ascorbic acid $(1-40 \mu \mathrm{g} / \mathrm{mL})$ dissolved in ethanol. Hemolysis of RBCs was carried out by mixing a 3\% suspension of RBCs (unmodified or modified) in a phosphate buffer $(\mathrm{pH}=7.4)$ with AAPH solution (final concentration $40 \mathrm{mmol} / \mathrm{L}$ ). This reaction mixture was incubated at $37^{\circ} \mathrm{C}$ for $3 \mathrm{~h}$. After incubation, the samples were centrifuged at $23^{\circ} \mathrm{C}(2000 \times \mathrm{g})$ for $15 \mathrm{~min}$. The extent of hemolysis was determined spectrophotometrically by measuring the absorbance of the supernatant at $540 \mathrm{~nm}$. For reference, RBCs were treated with redistilled water and the absorbance of the hemolysate was used as 100\% hemolysis. The percentage of hemolysed cells was calculated as the ratio of absorbance of extract's modified and AAPH oxidized cells to the absorbance of unmodified and AAPH oxidized cells (control). The $\mathrm{IC}_{50}$ value of extract, responsible for $50 \%$ inhibi- 
tion of hemolysis induced by AAPH, was determined and was compared with $\mathrm{IC}_{50}$ values determined for standard antioxidant $\mathrm{L}(+)$ ascorbic acid and procyanidin $\mathrm{B}_{3}$.

\section{Microscopic studies of erythrocyte shapes}

The impact of the extract on the shape of erythrocytes was determined by using the optical microscope and scanning electron microscope (SEM).

After separating from plasma, the red cells were washed four times in a $0.9 \% \mathrm{NaCl}$ solution in order to study them with the optical microscope. Next, the erythrocyte solution at $2 \%$ hematocrit was incubated with kiwi leaves extract used at 0.01 and $0.1 \mathrm{mg} / \mathrm{mL}$ for $1 \mathrm{~h}$ at $37^{\circ} \mathrm{C}$. After this modification, a $0.2 \%$ solution of glutaraldehyde was added to the erythrocytes to fix them. The red cells thus prepared were observed under a biological optical microscope (Nikon Eclipse E200) equipped with a digital camera. On the basis of the obtained photographs, the percentage of the two basic forms, i.e. echinocytes and stomatocytes, in a population of $c a$. 800 cells was specified. Individual forms of erythrocyte cells were ascribed morphological indices according to the Bessis scale [Bernhardt \& Ellory, 2003; Bessis, 1997]. Negative values from -1 to -4 were ascribed for stomatocytes and positive ones from 1 to 4 for echinocytes.

For study with the electron microscope the erythrocytes were prepared in a way similar to that of optical microscope but slightly modified. After incubating the erythrocytes with the extract, the cells were fixed in a $2.5 \%$ solution of glutaraldehyde for $48 \mathrm{~h}$. Next, the phosphate buffer was used for washing the cells for $20 \mathrm{~min}$, followed by a rising series of acetone concentrations $(30,50,60,70,80,90$ and $100 \%)$ in order to dehydrate the cells. Every sample was washed for $15 \mathrm{~min}$ in a proper concentration of acetone, and next left in pure acetone for $30 \mathrm{~min}$. After that, red cells were dried at $23^{\circ} \mathrm{C}$ for $12 \mathrm{~h}$. The prepared cells were deposited on object stages and subjected to X-ray microanalysis by means of an X-ray analyzer (Brucker AXS Quantax) combined with the ESPRIT ver. 1.8.2. software. The Scancoat 6 (Edwards, London) sprinkler was used to coat the samples with gold. To analyze material ultrastructure, we used a scanning microscope (EVO LS15 ZEISS) with SE1 detector, under high vacuum and accelerating voltage of $\mathrm{EHT}=20 \mathrm{kV}$.

\section{Spectrophotometric assays for cytotoxic and antiproliferative activities - MTT test}

The antiproliferative and toxic activity of the kiwi leaves extract in relation to mouse lymphoma T-cells were determined in MTT (3-(4,5-dimethylthiazol-2-yl)-2,5-diphenyltetrazolium bromide) assays. The cells $6 \times 10^{3} /$ well for antiproliferative assay or $2 \times 10^{4} /$ well for cytotoxic assay in $50 \mu \mathrm{L}$ of the medium were added into 96-well, flat-bottom culture plates. Next, the extract dissolved in ethanol $(10 \mathrm{mg} / \mathrm{mL})$ and diluted in $100 \mu \mathrm{L}$ of the culture medium of increasing concentrations from 1 to $400 \mu \mathrm{g} / \mathrm{mL}$ were added to the cells which were further incubated at $37^{\circ} \mathrm{C}$ for $72 \mathrm{~h}$ and $24 \mathrm{~h}$ for antiproliferative and cytotoxic assay, respectively. At the end of the incubation period, $15 \mu \mathrm{L}$ of $5 \mathrm{mg} / \mathrm{mL}$ MTT solution were added to each well and the cells were incubated at $37^{\circ} \mathrm{C}$ for $4 \mathrm{~h}$. After incubation, $100 \mu \mathrm{L}$ of sodium dodecyl sulfate
(10\% SDS in 0.01 mol.L HCl) were added and the plates were further incubated overnight. The cell growth was then determined spectrophotometrically by measuring the absorbance at $550 \mathrm{~nm}$ (ref. $630 \mathrm{~nm}$ ) with a Multiscan EX ELIXA reader (ThermoLabsystem, Cheshire, WA, USA). Inhibition of cell growth $\left(\mathrm{I}_{\mathrm{cg}}\right)$ was determined according to the formula:

$$
I_{c g}=\frac{A_{\text {cell modified }}-A_{\text {medium modified }}}{A_{\text {cell control }}-A_{\text {medium }}} \times 100 \%
$$

\section{Flow cytometry assay for reversal of MDR in mouse lymphoma cells}

The impact of the extract on MDR reversal was determined by treating the mouse lymphoma L5178Y cells transfected with the human MDR1 gene with different concentrations of kiwi leaves extract. The rhodamine-123 accumulation test was used. In general, the $\mathrm{pHa}$ MDR1/A retrovirus was used to infect the L5178 mouse T-lymphoma cells. By way of culturing the infected cells with $60 \mathrm{ng} / \mathrm{mL}$ colchicine, the MDR-1-expressing cell lines were obtained. Both MDR and PAR (parent) were grown in McCoy's 5A medium with $10 \%$ heat-inactivated horse serum supplemented with L-glutamine and antibiotics (penicillin/streptomycin solution). The final density of the cells in the samples was $2 \times 10^{6} / \mathrm{mL}$, and they were resuspended in the serum-free McCoy's 5A medium and distributed in $0.5 \mathrm{~mL}$ aliquots into the Eppendorf centrifuge tubes. Next, to the cell solutions the kiwi extract (dissolved in ethanol) was added, to the final concentrations of 40 and $400 \mu \mathrm{g} / \mathrm{mL}$, and the cells were incubated for $10 \mathrm{~min}$ at room temperature. Verapamil, treated as a standard MDR modulator, was used as a positive control. Next, the cells were incubated with $10 \mu \mathrm{L}$ (5.2 $\mu \mathrm{mol} / \mathrm{L}$ final concentration) of rhodamine 123 (an indicator) for further $20 \mathrm{~min}$ at $37^{\circ} \mathrm{C}$, washed twice and re-suspended in $0.5 \mathrm{~mL}$ phosphate buffered saline (PBS) for analysis. A flow cytometer (Beckton-Dickinson FACS scan) was used to measure the light scattering and fluorescence of the cell population. On the basis of the obtained results the forward scatter count (FCS) and side scatter count (SSC) that depend on size, shape and optical homogeneity of the cells were determined. Furthermore, the percentages of the control mean fluorescence intensity were calculated for MDR and parental (PAR) cells as compared with untreated cells. The fluorescence activity ratio (FAR) was calculated from the measured fluorescence values using the following formula:

$$
F A R=\frac{M D R_{\text {treated }} / M D R_{\text {control }}}{P A R_{\text {treated }} / P A R_{\text {control }}}
$$

\section{Statistical analysis}

Statistical analysis of results was performed using the STATISTICA 12.0 (StatSoft PL) software. For results obtained from microscopic and anti-hemolytic tests, the statistical analysis was conducted using the Dunnett test (post-hoc test - ANOVA) at a significance level $\alpha=0.01$ or $\alpha=0.05$. Statistical analysis of results obtained from studies with lymphoma cells was conducted using Student's t-test with the accepted level of significance at $\alpha=0.05$. All the experiments were done in at least three replicates, the results being presented as mean \pm standard deviation. 


\section{RESULTS AND DISCUSSION}

The extract was prepared from the leaves of Actinidia argute obtained from the Garden of Medicinal Plants herbarium of the Medical University in Wroclaw, Poland. The content of phenolic substances in the extract was analyzed by using liquid chromatography UPLC/DAD and UPLC/ ESI/MS methods and is ca. $600 \mathrm{mg}$ in $1 \mathrm{~g}$ of preparation [Cyboran et al., 2014]. The main polyphenolic components of the extract include different phenolic acids (neochlorogenic and chlorogenic acid, cryptochlorogenic), catechin, quercetin and kaempferol glycosides and, in particular, the B-type procyanidin dimers of high biological activity which constitute ca. $25 \%$ of the identified polyphenolic compounds.

\section{Spectrophotometric assay for anti-hemolytic activity}

By using spectrophotometric methods, the anti-hemolytic activity of the extract was determined on the basis of the concentration of hemoglobin released from cells damaged by oxidation. The obtained results showed that kiwi leaves extract effectively protects erythrocytes against the adverse effects of free radicals, because a concentration-dependent decrease in hemolysis of erythrocytes was observed (Figure 1). Procyanidin $\mathrm{B}_{3}-$ one of the most active extract constituents, and $\mathrm{L}(+)$ ascorbic acid - the standard hydrophilic antioxidant, were included into this investigation. The $\mathrm{IC}_{50}$ value of kiwi leaves extract, procyanidin $\mathrm{B}_{3}$, and $\mathrm{L}(+)$ ascorbic acid responsible for $50 \%$ inhibition of AAPH-induced hemolysis of erythrocytes were as follows: $6.89 \pm 0.64,2.50 \pm 0.12$ and $32.57 \pm 1.16 \mu \mathrm{g} / \mathrm{mL}$, respectively. The results indicate that procyanidin $\mathrm{B}_{3}$ better protects cells from damage induced by free radicals than the extract, but both the extract and procyanidin $B_{3}$ are much more effective than the standard hydrophilic antioxidant which is ascorbic acid.

Similar results, i.e. higher activity of procyanidin $\mathrm{B}_{3}$ than that of the extract, were observed in our previous work, where

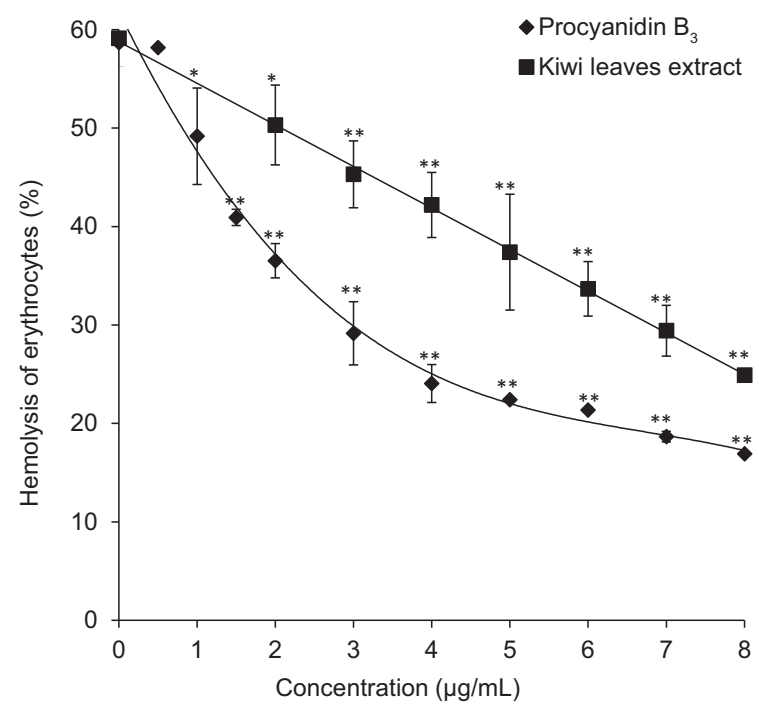

FIGURE 1. Percentage of hemolysed cells vs. concentration of kiwi leaves extract and its constituent procyanidin $\mathrm{B}_{3}$. Statistical analysis was conducted using the Dunnett test. Statistically significant results are denoted, respectively: ${ }^{*} \alpha=0.05,{ }^{* *} \alpha=0.01$. we examined the antilipoperoxidant activity of kiwi leaves extract and procyanidin $\mathrm{B}_{3}$ [Cyboran et al., 2014]. Furthermore, B type procyanidin dimers constitute about $25 \%$ of extract ingredients [Cyboran et al., 2014]. Therefore, to establish if activity of procyanidin is modified by other extract components, we compared the activity of procyanidin $\mathrm{B}_{3}$ used at a concentration of $2 \mu \mathrm{g} / \mathrm{mL}$ with the activity of extract used
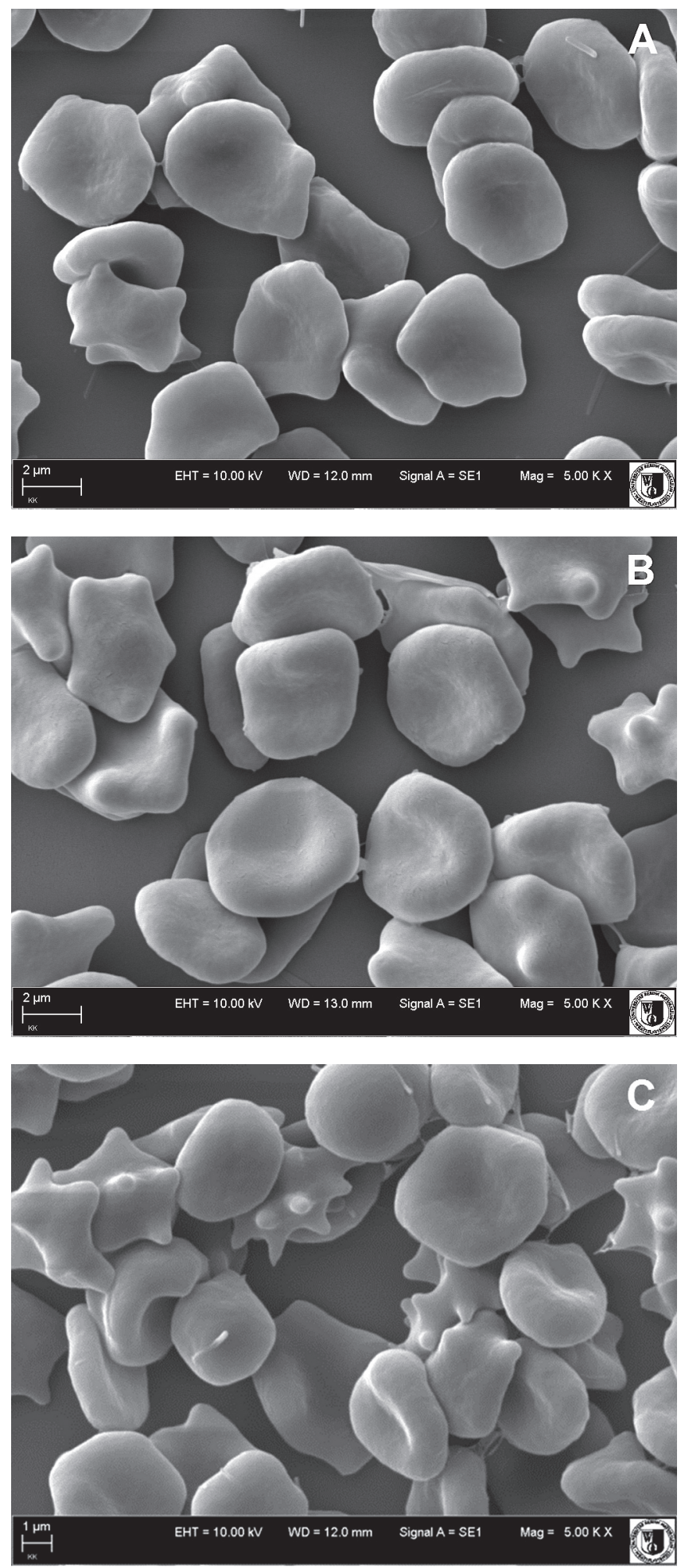

FIGURE 2. Shapes of unmodified erythrocytes (A) and those modified with kiwi leaves extract used at the concentration of $0.01 \mathrm{mg} / \mathrm{mL}$ (B) and $0.1 \mathrm{mg} / \mathrm{mL}(\mathrm{C})$, observed with an electron microscope. 
at $8 \mu \mathrm{g} / \mathrm{mL}$ (the same procyanidin concentration). The results included in Figure 1 clearly indicate that procyanidin $\mathrm{B}_{3}$ in the extract better protects erythrocytes against oxidative damage than when used alone. The obtained results confirm that biological activity, in particular antioxidant/anti-hemolytic activity, of the extract depends not only on the number, amount, and type of its constituents but also on their mutual interaction. Hence extract components, by preserving whole erythrocytes and their membrane phospholipids intact, and due to their anti-hemolytic and antilipoperoxidant activity, may maintain in vivo the integrity of RBC in capillaries and effectively counteract free radical damage.

\section{Microscopic studies of erythrocyte shapes}

To determine the location of extract constituents in the erythrocyte membrane, their impact on the shape of erythrocytes was examined. The study was conducted using an electron and optical microscope, coupled with a digital camera. Sample photographs of the blood cells (control and extract's modified) taken with the electron microscope are shown in Figures 2 (A), (B) and (C).

The photographs registered by using the optical microscope allow to quantify the individual forms of erythrocytes in a population of 800 cells. The classification of shapes was carried out based on the scale of Bessis \& Brecher [Bernhardt \& Ellory, 2003; Bessis, 1997], where specific shapes are assigned the following morphological indexes: spherostomatocytes (-4), stomatocytes II (-3), stomatocytes I (-2), discostomatocytes (-1), discocytes (0), discoechinocytes (1), echinocytes (2), spheroechinocytes (3), and spherocytes (4). Figure 3 shows the percentage of specific shapes of erythrocytes modified with the kiwi leaves extract at 0.01 and $0.1 \mathrm{mg} / \mathrm{mL}$ concentrations.

The obtained results have shown that erythrocytes modified by the extract used at $0.01 \mathrm{mg} / \mathrm{mL}$ practically do not differ from control cells. At a higher extract concentration

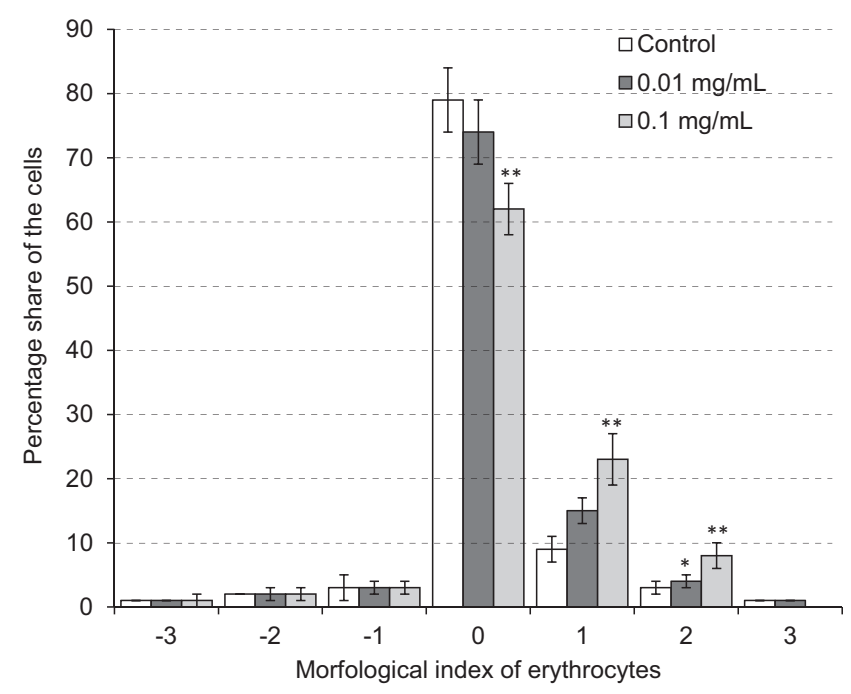

FIGURE 3. Mean percentage of erythrocyte shapes formed in the presence of kiwi leaves extract applied at $0.01 \mathrm{mg} / \mathrm{mL}$ and $0.1 \mathrm{mg} / \mathrm{mL}$. Statistical analysis was conducted using the Dunnett test. Statistically significant results are denoted, respectively: ${ }^{*} \alpha=0.05,{ }^{* *} \alpha=0.01$.
TABLE 1. Optical density of cancer cells non-treated (control) and incubated for 24 and $72 \mathrm{~h}$ with different concentrations of Actinidia arguta leaf extract in the MTT assay.

\begin{tabular}{lcc}
\hline $\begin{array}{l}\text { Concentration } \\
(\mu \mathrm{g} / \mathrm{mL})\end{array}$ & $\begin{array}{c}\text { Incubation time } \\
24 \mathrm{~h}\end{array}$ & $\begin{array}{c}\text { Incubation time } \\
72 \mathrm{~h}\end{array}$ \\
\hline 0 (control) & $0.515 \pm 0.056$ & $0.630 \pm 0.051$ \\
1 & $0.512 \pm 0.041$ & $0.612 \pm 0.037$ \\
10 & $0.527 \pm 0.050$ & $0.600 \pm 0.051$ \\
25 & $0.505 \pm 0.031$ & $0.675 \pm 0.062$ \\
50 & $0.505 \pm 0.040$ & $0.635 \pm 0.041$ \\
100 & $0.528 \pm 0.048$ & $0.660 \pm 0.043$ \\
200 & $0.497 \pm 0.041$ & $0.625 \pm 0.058$ \\
400 & $0.485 \pm 0.062$ & $0.694 \pm 0.072$ \\
\hline
\end{tabular}

$(0.1 \mathrm{mg} / \mathrm{mL})$ a decrease were observed in the number of discocites and increase in the number of discoechinocytes (1) and echinocytes (2). The formation of echinocytes means, according to the Sheetz and Singer theory [Sheetz \& Singer, 1974], that extract components may bind only to the outer monolayer of erythrocyte membrane. Our earlier studies showed changes in membrane fluidity and packing order of the polar heads of lipids of the erythrocyte membrane caused by a mini-kiwi leaves extract [Cyboran et al., 2014]. Literature data indicate that various phenolic extracts and free phenolic compounds, that are able to modulate the hydrophilic and hydrophobic parts of erythrocyte membrane, can induce changes in erythrocyte shape [Bonarska-Kujawa et al., 2015; Suwalsky et al., 2007], this being in good agreement with our results. The main extract ingredients, like procyanidin $\mathrm{B}_{3}$ or chlorogenic acid, used at the same concentration as that in the extract, induce the formation of echinocytes to a much greater extent (results not included). Taking into account this result, the slight induction of echinocytes caused by the extract is probably due to the presence of other compounds which have a lower affinity to the membrane. It is possible, because among the polyphenolic components of the extract, aside of monomers and procyanidin dimers which are readily identified by HPLC methods, there might also occur procyanidin oligomers which have been detected in, e.g., a hydroalcoholic extract from plants of the Actinidia family [Pinelli et al., 2013]. Due to their size, such components are not expected to penetrate deep into the membrane but can interact with its surface. The presence of such compounds can also impair binding of other compounds which exhibit that ability, i.e. B type procyanidins or phenolic acids, to the membrane.

\section{MTT cytotoxicity assay}

The in vitro research on antiproliferative and toxic activity of the kiwi leaves extract in relation to the mouse lymphoma cell line was done by using an MTT assay. The results of both experiments ( 24 and $72 \mathrm{~h}$ ) are shown in Table 1. The optical density of cancer cells in the presence of $1-400 \mu \mathrm{g} / \mathrm{mL}$ kiwi extract was from 0.512 to 0.485 after $24 \mathrm{~h}$ and from 0.612 to 0.694 after $72 \mathrm{~h}$, respectively, whereas the values determined for the control non-treated cells were from 0.515 after $24 \mathrm{~h}$ to 
TABLE 2. Flow-cytometric analysis of the effect of Actinidia arguta leaf extract on rhodamine 123 accumulation of human MDR gene transfected mouse lymphoma cells.

\begin{tabular}{l|c|c|c|c|c}
\hline Sample & Concentration $(\mu \mathrm{g} / \mathrm{mL})$ & FSC $^{\mathrm{c}}$ & SSC $^{\mathrm{d}}$ & Mean & FAR $^{\mathrm{e}}$ \\
\hline PAR $^{\mathrm{a}}$ & - & 1917 & 1688 & 94.7 & - \\
MDR $^{\mathrm{b}}$ & - & 2167 & 877 & $\mathbf{2 . 0 3}$ & - \\
Verapamil & 10 & $2077^{*}$ & $800^{*}$ & $33.6^{* *}$ & $\mathbf{1 6 . 5 5}$ \\
Kiwi leaf extract & 40 & 2168 & 891 & 1.75 & $\mathbf{0 . 8 6}$ \\
Kiwi leaf extract & 400 & $2074^{* *}$ & $1002^{*}$ & $2.76^{*}$ & $\mathbf{1 . 3 5}$ \\
\hline
\end{tabular}

${ }^{\mathrm{a}}$ parental cells without transfection of MDR1 gene; ${ }^{\mathrm{b}}$ parental cells transfected with MDR 1 gene; ${ }^{\mathrm{F} S C}$ - forward scatter count (cell size ratio); ${ }^{\mathrm{S} S S C}$ side scatter count; ${ }^{\mathrm{e}} \mathrm{FAR}$ - fluorescence activity ratio.

${ }^{*}$ Statistical analysis was conducted using the Student's t-test. Statistically significant results are denoted, respectively: ${ }^{*} \mathrm{p}<0.05,{ }^{* *} \mathrm{p}<0.01$.

0.630 after $72 \mathrm{~h}$. The inhibition of cells grown $\left(\mathrm{I}_{\mathrm{cg}}\right)$ calculated on the basis of these results was less than $2 \%$ and indicated that, in the applied concentrations, the compounds contained in the extract had no antiproliferative and cytotoxic effect on mouse lymphoma cells.

\section{Assay for the reversal of MDR in mouse lymphoma cells}

The effects of the extract on reversion of multidrug resistance in the L5178Y mouse T-cell lymphoma drug-sensitive (parent) and multidrug resistant (MDR) cells were examined. The well-known MDR modifier verapamil was used as a control. The reversal effect was determined on the basis of the calculated fluorescence activity ratio (FAR) between treated and untreated groups of cells. The kiwi extract was ineffective at both applied concentrations, because the FAR values calculated for the extract-modified cells were less than MDR means and also several times lower than the values calculated for verapamil-treated cells (Table 2). It means that the extract was ineffective as a resistance modifier of lymphoma cells. However, the slightly increased values of side scatter count (SSC is proportional to cell granularity) and slightly decreased values of forward scatter count (FCS) obtained for the extract-modified cells compared to the control (Table 2) may refer to some non-specific membrane effects.

This research has shown that the kiwi leaves extract, despite the high content of procyanidins and other phenolic compounds, is ineffective as a resistance modifier of lymphoma cells, because its ingredients have no inhibitory effect of P-glycoprotein. However, this result indicates that the extract can interact with lymphoma cells in an unspecific way, because it caused a slight change in cell granularity and cell size. However, this observation requires more accurate and detailed research. This study proves that the well-documented anticancer/cytotoxic activity of procyanidins strongly depends on mutual interaction between them and other phenolic compounds, when present in a mixture and also on the type of cancer cells. In future studies, the fraction of procyanidins should be isolated from the kiwi leaves extract and their biological activity examined in order to determine the suitability of those compounds, not only in the prevention of diseases but also in the treatment of cancer cells.

\section{CONCLUSION}

Kiwi leaves extract has high anti-hemolytic activity and ability to modulate the physical properties of the cells. The extract effectively protects erythrocytes from oxidative damage caused by water-soluble free radicals. Its ingredients bind to the cell membrane, change its physical properties, inducing alteration in the shape of erythrocytes, and slightly affect granularity and size of lymphoma cells. Owing to the binding they may form a barrier on the membrane which protects against the harmful effect of free radicals. On the other hand, the B type procyanidins contained in a large amount in the extract, of documented anticancer activity, are nontoxic and do not exhibit the antiproliferative activity with respect to lymphoma cells and do not affect their multidrug resistance. The extract from the leaves of the kiwi may find an application in the prevention of diseases especially those caused by the oxidative stress. Furthermore, it may be a useful material for obtaining procyanidins, which after further research may prove effective against tumor cells, as it has been in the case of procyanidins contained in kiwi fruit.

\section{ACKNOWLEDGEMENTS}

We are grateful to Mrs. Anikó Vigyikán Váradi for the preparation of the tissue cultures and technical assistance, and to Imre Ocsovszki for the flow cytometric measurements.

\section{STUDY FUNDING}

This work was supported from funds of the statutory activities of the Department of Physics and Biophysics, Wroclaw University of Environmental and Life Sciences. The study was also supported by Szeged Foundation for Cancer Research, by the project TAMOP-4.2.2A- 11/1/KONV-2012- 0035.

\section{CONFLICT OF INTEREST}

The authors declare no conflicts of interest. 


\section{REFERENCES}

1. Akhtar S., Meeran S.M., Katiyar N., Katiyar S.K., Grape seed proanthocyanidins inhibit the growth of human non-small cell lung cancer xenografts by targeting insulin-like growth factor binding protein-3, tumor cell proliferation and angiogenic factors. Clin. Cancer Res., 2009, 15, 821-831

2. Becker P.S., Cohen C.M., Lux S.E., The effect of mild diamide oxidation on the structure and function of human erythrocyte spectrin. J. Biol. Chem., 1986, 261, 4620-4628.

3. Bernhardt I., Ellory J.C. (eds.), Membrane lipids and proteins as a basis of red cell shape and its alterations. 2003, in: Red Cell Membrane Transport in Health and Disease. Berlin: Springer-Verlag, pp. 26-60.

4. Bessis M., Erythrocyte form and deformability for normal blood and some hereditary hemolytic anemias. Nouv. Rev. Fr. Hematol., 1997, 18, 75-94.

5. Bonarska-Kujawa D., Pruchnik H., Cyboran S., Żyłka R., Oszmiański J., Kleszczyńska H., Biophysical mechanism of the protective effect of blue honeysuckle (Loniceracaerulea $L$. var. kamtschatica Sevast.) polyphenols extracts against lipid peroxidation of erythrocyte and lipid membranes. J. Membr. Biol., 2012, 247, 611-625.

6. Bonarska-Kujawa D., Cyboran-Mikołajczyk S., Kleszczyńska H., Molecular mechanism of action of chlorogenic acid on erythrocyte and lipid membrane. Mol. Membr. Biol., 2015, 32, 46-54.

7. Borst J.W., Visser N.V., Kouptsova O., Visser A.J.W.G., Oxidation of unsaturated phospholipids in membrane bilayer mixtures in accompanied by membrane fluidity changes. Biochim. Biophys. Acta, 2000, 1487, 61-73.

8. Buchwald H., O’Dea T.J., Menchaca H.J., Michalek V.N., Rohde T.D., Effect of plasma cholesterol on red blood cell oxygen transport. Clin. Exp. Pharmacol. Physiol., 2000, 27, 951-955.

9. Chai W.M., Shi Y., Feng H.L., Xu L., Xiang Z.H., Gao Y.S., Chen Q.X., Structure characterization and anti-tyrosinase mechanism of polymeric proanthocyanidins fractionated from kiwifruit pericarp. J. Agric. Food Chem., 2014, 62, 6382-6389.

10. Chung Y.C., Huang C.C., Chen C.H., Chiang H.C., Chen K.B., Chen Y.J., Liu C.L., Chuang L.T., Liu M., Hsu C.P., Grape-seed procyanidins inhibit the in vitro growth and invasion of pancreatic carcinoma cells. Pancreas, 2012, 41, 447-454.

11. Cyboran S., Oszmiański J., Kleszczyńska H., Modification of the properties of biological membrane and its protection against oxidation by Actinidia arguta leaf extract. ChemBiol. Interact., 2014, 222, 50-59.

12. Fofie C.K., Wansi S.L., Nguelefack-Mbuyo E.P., Atsamo A.D., Watcho P., Kamanyi A., Nole T., Nguelefack T.B., In vitro anti-hyperglycemic and antioxidant properties of extracts from the stem bark of Ceiba pentandra. J. Complement. Integr. Med., 2014, 11, 185-193.

13. Hale J., Winlove C.P., Petrov P.G., Effect of hydroperoxides on red blood cell membrane mechanical properties. Biophys. J., 2011, 101, 1921-1929.

14. He L., Zhao C., Yan M., Zhang L.Y., Xia Y.Z., Inhibition of P-glycoprotein function by procyanidin on blood-brain barrier. Phytother. Res., 2009, 23, 933-37.
15. Kaur R., Kaur J., Mahajan J., Kumar R., Arora S., Oxidative stress-implications, source and its prevention. Environ. Sci. Pollut. Res., 2014, 21, 1599-1613.

16. Kaur M., Mandair R., Agarwal R., Agarwal C., Grape seed extract induces cell cycle arrest and apoptosis in human colon carcinoma cells. Nutr. Cancer, 2008, 60 Suppl., 2-11.

17. Montoya C.A., Rutherfurd S.M., Olson T.D., Purba A.S., Drummond L.N., Boland M.J., Moughan P.J., Actinidin from kiwifruit (Actinidia deliciosa cv. Hayward) increases the digestion and rate of gastric emptying of meat proteins in the growing pig. Brit. J. Nutr., 2014, 111, 957-967.

18. Motohashi N., Shirataki Y., Kawase M., Tani S., Sakagami H., Satoh K., Kurihara T., Nakashima H., Mucsi I., Varga A., Molnár J., Cancer prevention and therapy with kiwifruit in Chinese folklore medicine: a study of kiwi fruit extracts. J. Ethnopharmacol., 2002, 81, 357-364.

19. Pinelli P., Romani A., Fierini E., Remorini D., Agati G., Characterization of the polyphenol content in the kiwifruit (Actinidia deliciosa) exocarp for the calibration of a fruit-sorting optical sensor. Phytochem. Anal., 2013, 24, 460-466.

20. Senguttuvan J., Paulsamy S., Karthika K., Phytochemical analysis and evaluation of leaf and root parts of the medicinal herb Hypochaeris radicata $L$. for in vitro antioxidant activities. Asian Pac. J. Trop. Biomed., 2014, 4 Suppl., S359-67.

21. Sheetz M.P., Singer S.J., Biological membranes as bilayer couples. A molecular mechanism of drug-erythrocyte interactions. Proc. Natl. Acad. Sci., 1974, 71, 4457-4461.

22. Suwalsky M., Orellana P., Avello M., Villena F., Sotomayor C.P. Human erythrocytes are affected in vitro by extracts of Ugni molinae leaves. Food Chem. Toxicol., 2006, 44, 1393-1398.

23. Suwalsky M., Orellana P., Avello M., Villena F., Protective effect of Ugni molinae Turcz against oxidative damage of human erythrocytes. Food Chem. Toxicol., 2007, 45, 130-113.

24. Szabó D., Keyzer H., Kaiser H.E., Molnár J., Reversal of multidrug resistance of tumor cells. Anticancer Res., 2000, 20(6B), 4261-4274.

25. Szabó D., Molnár J., The role of stereoselectivity of chemosensitizers in the reversal of multidrug resistance of mouse lymphoma cells. Anticancer Res., 1998, 18(4C), 3039-3044.

26. Valko M., Leibfritz D., Moncol J., Cronin M.T.D., Mazur M., Telser J., Free radicals and antioxidants in normal physiological functions and human disease. Int. J. Biochem. Cell. Biol., 2007, 39, 44-84.

27. Zhao B.X., Sun Y.B., Wang S.Q., Duan L., Huo Q.L., Ren F., Li G.F. Grape seed procyanidin reversal of P-glycoprotein associated multi-drug resistance via down-regulation of NF- $\mathrm{BB}$ and MAPK/ERK mediated YB-1 activity in A2780/T cells. PLoS One, 2013, 8(8):e71071.

28. Zuo L.L., Wang Z.Y., Fan Z.L., Tian S.Q., Liu J.R., Evaluation of antioxidant and antiproliferative properties of three Actinidia (Actinidia kolomikta, Actinidia arguta, Actinidia chinensis) extracts in vitro. Int. J. Mol. Sci., 2012, 13, 5506-5518.

Submitted: 9 December 2016. Revised: 21 March, 9 May, and 24 May 2017. Accepted: 26 May 2017. Published on-line: 13 September 2017. 